\title{
Equipping Students to Join the Literary Conversation: Learning Literary Language in Workshops
}

\author{
Jenifer DeBellis \\ Solstice M.F.A. of Pine Manor College, Chestnut Hill, USA \\ Email: jenifer.debellis@gmail.com
}

How to cite this paper: DeBellis, J. (2019) Equipping Students to Join the Literary Conversation: Learning Literary Language in Workshops. Open Access Library Journal, 6: e4832.

https://doi.org/10.4236/oalib.1104832

Received: August 13, 2018

Accepted: February 16, 2019

Published: February 19, 2019

Copyright $\odot 2019$ by author(s) and Open Access Library Inc.

This work is licensed under the Creative Commons Attribution International License (CC BY 4.0).

http://creativecommons.org/licenses/by/4.0/

\section{(c) (i) Open Access}

\begin{abstract}
An often overlooked and undervalued component of disciplinary studies is the way learning and growth are informed by how fluently students understand the discipline's language. It is difficult, and often impossible, for someone to engage in conversations if she or he cannot speak the language. It is thus difficult to feel a sense of belonging to a community if one cannot join its conversations. This scholarly work analyzes a term I call literary language, which is a literary term-based language informed by literary and rhetorical strategies. Students learn when they are active participants in their learning process. They cannot fully engage in this learning if they do not know the discourse's language. For students to become better compositional and creative writers, they need opportunities to learn literary language and participate in larger craft-specific discussions. Spaces that invite students-in their various learning stages - to read like writers, think like writers, and write like writers help them learn, retain, and apply literary language in its intended context. The research included in this pedagogical study tests and analyzes face-to-face, online, and hybrid workshop learning models, which rely on learner-centered strategies that help students accurately and easily understand and use literary language. This fluency allows them to fully immerse themselves in their academic communities where they can begin to take pride in learning its cultural values and language so they can blend into this new world like they always belonged.
\end{abstract}

\section{Subject Areas}

Literature

\section{Keywords}

Writing Workshops, Literary Language, Learner-Centered, Best Practices 


\section{Introduction}

Literary language, like any other language, has its own set of common words, phrases, terms, meanings, and interpretations. Anyone who has ever listened to a conversation in a foreign language knows the importance of understanding, and how lack of understanding denies the listener entrance into the exchange. Learning another language fluently enough to understand it and engage in conversation takes time. To grow to comprehend and apply another language requires more than memorization, which relies on recall and recognition. Recall and recognition alone only allow for selective understanding. Learning the dynamics of another language is important if an individual desires to understand the community or group that uses this language. And if this same individual wants to gain entrance into this community's conversations, she needs to develop a fluent knowledge and use of the language.

As with any type of learning, a student must desire to learn and be an active participant in the different stages of development. However, are motivation, ambition, and hard work enough to ensure a student will learn to be fluent in the area of study? When it comes to literary language, can writing workshops be an effective means for students to learn and learn to apply literary terms? Does the workshop model have the potential to foster literary language fluency?

This essay explores the efficacy of face-to-face, online, and hybrid writing workshops in teaching students literary language and ways to use it. Workshop teaching models, which rely on learning through an integration of social and cognitive processes, provide socio-cognitive environments where complex learning can occur. Since a workshop invites students to move from an outsider to a full participant, a different type of learning occurs. Face-to-face, online, and hybrid workshops share many effective strategies for accelerating learning. These strategies will help educators build workshops that invite students (in their various learning stages) to join the creative conversation as they discover ways to learn, retain, and apply literary language.

\section{What Is Literary Language and where Is It Taught and Used?}

Before we dissect ways students can learn and use literary language, we must define what it is and why it is beneficial to know. All forms of writing are a means of communication. The communication that transpires through text on the page, screen, or any other medium becomes the language a reader needs to know to navigate the text. Literary language is a treatment of the text that aims to enhance the reading experience and/or reveal hidden meanings. As literary language adds something to the text it becomes a dialect of the text's language-a distinguished vernacular readers must parse to fully engage with the language as it has been presented. In a sense, readers must become translators. The act of reading then becomes the activity of experiencing the text while discovering meaning, be this surface or hidden meanings that are embedded in the text using 
literary and rhetorical devices. So, whether someone reads to learn or gain information, or for pure enjoyment or escape, the language of the text will have the same job: to guide the reader toward the intentions of the text.

Although literary language has its roots in the literary world, it is not exclusive to it. Literary language is created using literary devices that add depth and systems of potential meaning to a text. Literary language is (and has been) used in various forms of literature to encourage creative and critical thinking, promote language development, and mold social outlooks and behaviors. As culture and ways of learning and seeing the world have evolved, however, literary language has made its way into modes of learning and communication that extend beyond the literary world. No longer exclusive to literature, literary language is used in all types of rhetoric to enhance what is being conveyed. So, while it still plays a vital role in literature studies and creative writing, literary language also impacts journalism, advertisement, academic writing, professional media, sermons, television programming, gaming, and even an individual's daily social interactions. Literary language is used everywhere we look. And if literary language has become a part of everyday life, it makes sense for educational institutions to teach it to the students they are helping to mold into successful members of society.

As readers engage with the text they are also engaging with the author. The literary devices an author uses become an extension of the language of the text-the text being the original form of written communication that exists between the author and the reader. To create an engaging reading experience, the author employs these literary devices. It is the reader's job, then, to notice these devices to parse the language of the text. Authors can utilize any number of literary devices, and in any combination, to stimulate reader reaction. Sensuous devices are one way authors use literary language strategies to engage readers. Consider how sound devices such as assonance, consonance, alliteration, and onomatopoeia work to create sound sequences that evoke certain moods, environments, or musicality. A reader's reaction to these devices in a text will influence the reading experience. Advertisers, for instance, use sound devices to rouse certain reactions from their intended audience. One of Coca Cola's 2010 ad campaigns exemplifies text that relies on sound devices to evoke a sensation. The ad reads, "Twist the cap to refreshment" (Cohen, 2012) [1]. The onomatopoeic qualities of "twist" and "fresh" imitate the sound of carbonated soda when it is first opened. This ad begins with onomatopoeia and ends with a word that suggests customers' ultimate fulfillment with the product. Authors also rely on literary language strategies to manipulate language. When used to direct the text, the author communicates with readers by inviting them to notice things beyond the text's surface. A device like metaphor, for instance, can evoke deeper thought or convey symbolic depth that extends beyond the obvious elements and their surface meanings. This form of engagement also establishes interaction between the author and the reader, as the discovery that occurs through analysis often acts like a map. When a reader decodes a literary technique, she can find her way to a remote location that reveals the author's intentions. The reader, upon figur- 
ing out this hidden location, finds the author waiting there. Thus, when readers make the connections between the text and the literary elements at work in it, they are no longer simply reading the text: they are interacting with it. By employing the literary devices, the author anticipates this interaction with the reader. The author is saying, "Over here... I have something to show you." As the reader's senses and sensibilities are awakened through discovery, she enters an intimate space with the author where the writer's awe, intentions, motives, larger views, or fears have been tacked like notes on trees in the reader's journey. This type of reading experience is collaborative in that, as readers engage with the text and the literary devices, they are interacting with the author's textual intentions. Author/reader interaction is not always a meeting of the minds. Sometimes the discovery process is unpleasant. For instance, the devices in the text might provoke a reader to question what she has been shown. Such a reaction is equally interesting as it draws on a reader's critical thinking skills. In either case, the literary devices provoke an emotional response from a reader that engages her beyond the text's surface as the author intended.

The literary language in a text can also work to establish communication among readers. When a reader notices the language devices and begins to understand them, she can discuss these findings with other readers. In this instance the literary language works to elicit a larger conversation about what is going on in the work. Thus, the author has succeeded at paving a way to something embedded in the text worthy of notice and deeper discussion. A reader who understands literary language and the ways these devices work in the text can then collaborate with the author and other readers or peers. Unlike individual analysis, collaboration with other readers develops deeper conversations that rely on shared critical thinking. Each participant in these conversations can give voice to his or her observations and ways of seeing the world. Each participant in these conversations also has an opportunity to gain insight into how his or her peers observe and see the world. So, while the collaborative discourse that occurs in these deeper conversations works to decode larger truths about the text, it also has the potential to reveal larger truths about the world we share.

Whether students are reading to learn and exercise their critical thinking or learning to communicate and expand their understandings through their own writing, literary language plays an important role in learning processes. Reading and writing are two parts to a whole-the whole being text-based communication. We cannot talk about one without acknowledging the impact it has on the other. Beacon Literacy, one of Canada's leading non-profit reading organizations, nicely summarizes the reading and writing connection. Their web page states, "Reading and writing are fundamental skills that every individual needs to possess. They provide the foundations for almost every area of personal and economic development" (Literacy Canada) [2]. This reading-writing idea is not entirely new. Since literary language greatly impacts today's reading and writing forums, it is worthy of being included in the learning platform. Learning the language is as important as any other objective in equipping students to succeed 
personally and economically in school and life outside of school. Robert Scholes (1985) [3], Brown University Professor of English and Comparative Literature, claims the following about college students:

[they] exist in the most manipulative culture human beings have ever experienced. They are bombarded with signs, with rhetoric, from their daily awakenings until their troubled sleep, especially with signs transmitted by the audio-visual media. And, for a variety of reasons, they are relatively deprived of experience in the thoughtful reading and writing of verbal texts.

What students need from us ... is the kind of knowledge and skill that will enable them to make sense of their worlds, to determine their own interests ... to see through the manipulations of all sorts of texts in all sorts of media, and to express their own views in some appropriate manner. (pp. 15-16) [3]

An important element of fostering students to become better critical thinkers and compositional and creative writers is helping them learn literary language. Students can develop critical thinking skills by learning how to identify literary devices and parse their intended function in a text. For instance, juxtaposition is a literary device used in arguments across the disciplines to compare or contrast two items or ideas. Consider how students' literary understanding of juxtaposition impacts how they recognize parallels and analyze them in an academic text. When students learn the functions of literary devices, they are equipped with creative and critical strategies they can implement in their writing or contributions to class discussions.

The creative writing workshop model relies on students learning literary language through the reading-writing connection. An effective teaching model that focuses on reading to write is outlined in "Towards a New Poetics in Creative Writing Pedagogy," an essay developed by Dr. Paul Dawson (2003) [4], Lecturer in Creative Writing in the School of English at the University of New South Wales. A large focus in Dr. Dawson's teaching model is equipping students to read like writers, as they learn how to write by first reading. "Students are encouraged to read not merely for literary appreciations," Dawson says, "but with the aim of discovering ways to improve their own writing" (2003) [4]. Dawson's ideas about reading as a writer are influenced by nineteenth century historian and novelist Walter Besant and author-editor Dorothea Brande. In Besant's 1884 essay, "The Art of Fiction," he emphasizes how important it is for aspiring writers to carefully analyze well-received works to learn how they were crafted (as cited in Dawson, 2003) [4]. Similarly, Brande believes "reading as a writer" positively impacts the learning process. "In her handbook, Becoming a Writer, Brande advises that 'to read effectively it is necessary to learn to consider a book in the light of what it can teach you about the improvement of your own work"' (as cited in Dawson, 2003) [4]. Both ideas emphasize the significance of learning how others utilize literary language in a piece of writing. "Writers do not simply employ a neutral language to express their unified vision of the world, but in- 
stead represent within the literary work a range of extra-literary languages which organise social relations" (Dawson, 2003) [4]. Students need to read texts that employ "a range of extra-literary languages" in order to see literary writing modeled. Then, the literary knowledge students gain through reading helps mold the voice of their writing, regardless of the written forum.

Now that we can envision the usefulness of literary language, how can we teach students the language and ways to use it? Students need opportunities and spaces to practice the language. Courses focused on teaching composition, communications, literature, journalism, and creative writing comprise the primary spaces literary language is taught and used. As with any area of study, exposure to the discourse's basic language elements is a good place to begin. One way to expose students to literary language is to first introduce them to the terminology and then teach them how to recognize it within various texts. Once students can identify literary devices in a text, they can begin to analyze how the devices function. Two things occur concurrently during literary analysis. While students critically think to analyze the text, they also spend time with the language, dissecting its components and how they function in the writing. These strategies work together to reinforce learning the language. Teachers can further encourage learning by requiring students to apply literary terms to their analysis of mentor texts and peer work. When students use literary language to communicate their own ideas, they exercise their understanding of it. The more students practice using these terms in context, the more confident they become in using literary language. Students also gain confidence and understanding through essay writing that explores literary devices, as well as in-class or workshop discussions. Through deeper discussion the focus moves beyond the what to answer the how and why of the literary language. It is not enough for students to identify literary devices. Rather, the real discussion about context and meaning occurs when students are prepared to analyze the ways the language guides and manipulates the text. Peer discussion about literary devices and how the language operates in a text is another effective learning strategy. When students use literary language in written responses or group discussions, they move beyond memorizing a new concept. By encouraging students to use literary language in a workshop setting, they learn literary terminology and how the language devices inform the text through a shared experience.

\section{Defining the Workshop Teaching Model}

The word "workshop" is thrown around in pedagogical conversations so loosely I often wonder if educators are talking about the same teaching model. While one school of thought considers the workshop to be a place where a circle of peers workshop writing, others treat the workshop as a learning environment that incorporates multiple literary practices into one space. When considering what a workshop is "take the metaphor for what it was meant to convey. It alludes to practicality, to process, and to craft. It implies skills to be learned and 
tools to be maintained" (Gross, 2010, p. 54) [5]. A writing workshop offers teachers a model that is designed to get students reading like writers and writing like writers. Today's workshop model has evolved from the original Iowa Workshop Model first designed for graduate level writing students, which relied on a student body versed in literary studies and writing processes. In current academic settings, workshops are used to teach both undergraduate and graduate level compositional and creative writing. At the undergraduate level, students do not have the same writing and craft skills or literary knowledge. Since undergraduates require training in literary studies and writing processes, the original workshop model-with its primary focus on revision and honing craft-does not address all these learning needs. To place these ill-equipped students in a workshop situation when they do not know the discourse's language is to set them up to fail. "In the lower level creative writing workshops, students need to learn to employ the fundamental language of English studies" (LaFemina, May 2011) [6]. For this reason, many of today's workshops blend disparate reading and writing conventions that include instruction in basic literary knowledge, as well as ways for students to develop and revise writing. By borrowing from other literary traditions and discourses, the workshop has become a "hybrid" teaching model, which is "split between reading ['and all its corollary critical inquiries'] and its writing expectations" (Haake, 2010, p. 187) [7]. Such a teaching model opens the way for a new learning style.

Dr. Michael Gaffigan (March/April 1995) [8], in his essay "Reinventing the Undergraduate Poetry Workshop: Results from a Nationwide Survey of Undergraduate Poetry Writing Instructors," published by the Association of Writers and Writing Programs, stresses the importance of molding workshops to fit student needs at the respective college levels. "In undergraduate institutions," he states,

writing instructors implement a wide variety of practices in their classes beyond the basic workshop, primarily in response to the needs of their students, as many undergraduates have weak backgrounds in literature. Instructors often find that the traditional workshop is inadequate, and that the workshop must be supplemented with reading assignments, close readings and analysis of poems in class, discussions of poetics, exercises in prosody and form, and discussions of the writing process and strategies for revision. [8]

The major workshop components that mirror this model are analysis of mentor and peer texts, instruction on craft elements, generating new writing, and sharing writing at all developmental stages. Peer review of student writing is considered workshopping, which makes up a large portion of workshop interaction. To get students to critically respond to peer texts beyond their likes and dislikes, they need to learn literary language. Mentor texts provide teachers a learning tool for dissecting and analyzing well-developed works. These texts promote analysis of literary devices, which help students gain better under- 
standings of literary language. Mentor texts include anything from a professionally published literary or scholarly work, newspaper and internet articles, to a well-developed piece of student writing. While instructors often require individual written analysis of mentor texts, peer discussion of craft analysis is invaluable in a workshop. Not only do these craft discussions help students learn literary language and reinforce their understandings, they usually tie into the instructor's lesson on craft elements. The lesson then usually flows over to prompt writing that encourages the use of the device(s). Each workshop component plays into the others. When students share their writing and receive peer feedback, everything comes full circle so the cycle can begin again. Since students learn, use, and reinforce their understandings of literary language in each workshop stage, a well-rounded writing workshop will equip them to read and write like writers.

In her essay "Inquiry, Folkloristics, and Discussion: Unbinding Literature in the Classroom," Jacqueline Thursby (2002) [9], pedagogy scholar and Brigham Young University English Professor, talks about how students can learn literary language. Student engagement with the text is vital to learning in Thursby's praxis. "Unbinding literature" is a metaphor Thursby uses to explain how a certain type of learning occurs when students are taught to interact with the text. "'To unbind the text' means to unravel or undo elements that may otherwise be bound so tightly in the prose they are easily overlooked" (Thursby, 2002, p. 139) [9]. Thursby's literature teaching model focuses on unbinding the text in folklore. Yet, its focus on learning and using the language of a literary discourse can be adapted to fit any workshop setting. In the folklore teaching model, Thursby states, "unbinding the meaning of traditional vernacular folklore leads the reader more deeply into connotations woven through the text" (p. 139) [9]. These connotations can be suggested through a simple word choice, or through the installation of literary devices such as symbolism, allusion, plot, setting, recurring thematic elements, to name a few. Regardless of the device(s) used, students will need to understand the way literary devices function in a text in order to get at these connotations. For this teaching method to work, Thursby asserts, "the teacher will need to spend a few class periods helping the students to understand the basic concepts and elements of folklore" (p. 142) [9]. A well-managed class discussion is a great way to give students opportunities to learn language basics. Whether students talk or listen, everyone participates in a literary conversation. In this atmosphere, students learn as they engage in literary critique and observe the views of those around them. As students learn literary language and use this knowledge in literary analysis, they begin to see the language's function through a literary lens. This new way of seeing also impacts students' critical thinking skills.

My time as a teacher and student in writing workshops has allowed me to participate in environments where students regularly learn and use literary language. Educators can build many teaching strategies into a workshop where students learn and use literary language. Teachers can create assignments and 
writing prompts that encourage students to use the literary language they are expected to learn, grow to understand better, and apply to the larger conversations of work being discussed. Assignments such as close readings, reaction papers, and essays, poems, or short stories that incorporate specified literary elements all encourage students to use and explore the language. To help students learn meanings and functions of craft elements in literary works, teachers can use literary criticism. Teachers should consider whether the assigned reading will promote individual reflection and analysis, and if it has the potential to generate group discussion. Mentor texts are great resources as they promote analysis and model the types of writing we want students to mirror. Analysis of mentor texts can be handled in phases: individual assessment, critical review, and collaborative discussion all encourage students to learn literary language. Once a text is individually analyzed, students are prepared to collaboratively discuss the literary language. Since analysis encourages students to look carefully at writing strategies, they gain literary knowledge they can apply to their own writing. Mentor texts can also be dissected and used as mirror writing models, which allow students to mimic form, elements, and content by inserting their ideas into an already successful model. Another useful learning strategy in a workshop is to assign writing prompts that encourage the use of the literary devices being discussed. As students develop their own writing around literary devices they have been learning, they are exercising and expanding their understanding. Learning and using literary language does not end here. Students gain additional opportunities to learn and apply literary language when they share their writing in a workshop. The collaborative discussion here is similar to mentor text analysis, with one exception. In this discussion, peer review aims to celebrate what is working while decoding what is not working in the text so writers can address these things during revision. Every student learns something about literary language in these collaborative discussions of peer work-author and peer alike.

\section{The Many Masks of the Workshop Model}

Workshop models come in all shapes and sizes. Face-to-face, online, and hybrid styles are common types of workshops where literary language is taught and used. In all three workshop settings students analyze mentor texts and peer works to learn and learn to apply literary language. The workshop model allows for individual and group analysis. The latter allows students to collaborate ideas, perceptions, and concerns. A face-to-face workshop takes place in a physical classroom or similar meeting place. An online workshop exists entirely in a virtual Internet space. A hybrid workshop blends face-to-face and online workshop elements. Each one of these workshop styles has its advantages and disadvantages. However, each model can be set up to meet a diversity of student needs in limitless ways.

As a guest teacher in a middle school classroom in 2012, I taught a twelve-week folklore unit in a face-to-face workshop setting. The unit primarily focused on ways to learn and use literary language in workshop discussions and student 
writing. I developed my reading and writing unit around the writing workshop model, which included basic literary instruction and developing writing. Unlike Thursby (folkloric teaching model), I did not have a choice in the genre focus I taught. Yet, I could not have picked a style of writing that employs as many literary devices as folklore does. I was thrilled at the opportunities folklore offered students to learn and use literary language. To begin the unit, we spent some time talking about folklore's oral roots and the many literary elements that go into this genre's stories. The first day I also supplied the students with a handout of several literary terms we would focus on. We revisited this handout often, and added to it as we discovered literary devices that should be included on it.

The stories we discussed and analyzed were a mix of familiar and new folktales and represented a broad scope of cultural interests. In our initial discussions of familiar works, the students only had surface understandings of the stories. Student participation in these literary discussions was limited. Student responses resembled a book report more than a text analysis. It did not matter that students were familiar with the stories, as this familiarity did not enhance our discussions about what the texts were doing. Such a student reaction gave me an opportunity to test my theories about how literary language can be learned at a beginner level.

As I began to teach the students literary terms and help them identify devices in the text, everything about our workshop interaction changed. I noticed immediately that the literary instruction was working. The students were learning the language and gaining confidence in this new knowledge. The face-to-face collaboration allowed students to develop intimacy through personal interaction, which promoted an atmosphere of trust that enhanced learning. Personal contact also allowed me to assess body language to guide our discussions. When a student's facial expression revealed s/he was not following the discussion, I slowed the conversation and spent more time on that concept. Student participation grew from an average of three-to-four regular responders to all but three or four of the forty-nine students in the class eagerly adding to our discussions. Comments were no longer basic retellings of familiar story elements either. Student responses focused on craft and literary elements in the text.

Over the twelve-week unit, students developed and revised three pieces of writing. I analyzed every stage of the writing process, from the first draft to the finished, polished story. The growth between the first draft of the first piece and the first draft of the second piece was impressive. Not only did students use literary devices in their writing, they took more chances with their own creativity. In the first writing piece, most students chose to do an adaptation or react to a familiar piece of fiction, despite my encouragement and alternative prompt ideas. By the second assignment, most students developed a story that was uniquely theirs. Although I can only speculate about the shift in creative risk, I noticed students grew in their understanding of the language and demonstrated this in class activities and peer review. 
In 2011, I participated in an online peer tutoring workshop as an undergraduate at Oakland University. What was most striking about this experience was how student participation in the peer tutoring online workshop provided unique ways for us to learn literary language and reinforce our current knowledge. Since the web-based workshop relied on online responses and interactions, every student had to participate in all the discussions. Everyone in the online workshop had access to all the comments and contributed to the conversations. Our instructor used open and closed forums to post our reading materials and provide spaces for us to respond to course related questions and peer writing. In the open forums students had access to peer responses and comments prior to providing their own. In the closed forums students gained access to peer responses and comments only after they provided their own. An advantage of the closed forum was that students' initial responses were not influenced by peer or instructor contributions. Our online forum carried more in-depth discussions and covered more ground. Fewer time constraints allowed collaboration to go wherever our peer group was willing to take it, and this often meant we continued responding to each other days after the deadline.

Learning was enhanced in the online workshop because we could access multiple aids concurrently as we responded in the various forums. While many face-to-face environments utilize visual aids such as handouts and projector presentations, our online space also allowed us to simultaneously access multiple opened browsers by tiling them. These additional resources include external references, course materials, relevant texts, PowerPoint lectures, peer and instructor written responses, videos, pictures, or other such resources. Online forums enrich learning when students can view course materials, peer and instructor responses, and related visual aids and resources all on one screen at the same time they are generating their own responses. The time used to analyze and research literary terminology is lost in a typical, real time workshop environment. Control over pace meant students could edit their comments and synthesize their ideas before sharing them-a strategy I found myself exercising often. Control over pace also meant students could pause the current activity to look up a literary term or concept that was introduced to the conversation. This option proved invaluable since pausing is not feasible in a face-to-face environment as taking the time to look something up means losing focus and connection with the current, ongoing lesson or conversation. Pausing to look up things I did not know or understand enhanced the depth and speed at which I learned literary language.

In fall of 2012 I conducted a hybrid workshop with undergrad students. The workshop group consisted of four students, with me interacting as the fifth peer in the group. We had two face-to-face meetings during our four-week writing project, and all other interaction occurred in online forums. Although each student was at a different level in her writing development, we were all writers trying to improve our craft. Our conversations about craft elements and levels of 
writing were advanced compared to my middle school students. Our first session was a face-to-face meeting where we brought a piece of writing to share and had a collaborative discussion about craft elements and what was/was not working in each piece. The primary literary elements we agreed to focus on in our workshops were frameworks and recurring motifs, character/plot/narrative development, tension building devices, effect of symbolism and metaphor, and overall function of literary devices working together to drive the writing. This first face-to-face discussion allowed me to gauge where each student was in her writing life, as well as what types of interaction I could expect from each participant in the online forums.

Prior to beginning our online interaction, I shared the workshop guidelines based on our face-to-face brainstormed ideas. The guidelines outlined the craft elements peers should focus on while paying attention to how they functioned in the text. I instructed peers to focus their comments on what was and was not working in the prose or poem. I discouraged general comments unless they were backed by a brief explanation. We began our online interaction with a prompt for each participant to develop a short story or poem that utilized at least three literary elements from our list. Each participant had a week to develop a one-to-three page poem or short story and post it to the shared Google file. Representing a variety of writing styles, three of the pieces ended up being poems and two of them short stories. In the week that followed we read and analyzed the five peer pieces. I encouraged peers to react to each other's observations while they also added new ones of their own.

What I found interesting about the online workshop comments was how participants consistently discussed the dynamics of various devices without naming them. The peer interaction on Milica's story demonstrates how online discussions focused on the function of literary devices in the text without naming the devices. The protagonist in Milica's post-apocalyptic nature scene is hiding in a tree and has been commissioned to track someone with which she has a romantic history. One peer, Bethany, comments,

The solitude of this piece amplifies the emotion. The character's isolation in nature ... makes the reader attentive to the natural detail and magnifies each action. Gives me a strong sense of emotion and intrigues me to want to hear the whole story, what happened before and what happens afterwards.

Here, rather than naming devices, Bethany describes setting and plot elements and how they inform the protagonist's actions and cue the reader. Without naming in media res, Bethany also describes the effects of beginning in the middle of the story. Katie, another peer, builds on Bethany's comment, adding, "This sentence really puts you into the narrator's emotional state of mind. I also like how you dedicated some white space after this sentence-it seemed to amplify the narrator's sadness and isolation." Katie is talking about the effect of perspective in point of view without naming it, yet she clearly communicates how perspective, combined with strategic use of white space, influences readers' percep- 
tions.

In the final phase of the workshop's first round of writing, each peer responded to the comments posted on her piece. During this same week we had another face-to-face meeting where we brought another piece of writing to share and analyze. My primary purposes for this meeting were to promote personal contact to build trust within the group and for us to share additional work not included in the online forums. In this face-to-face meeting, we discussed ways recurring motifs mold a piece of writing, as well as all the devices that inform a theme's development. This topic opened our conversation up to a broad range of literary devices such as metaphor, imagery, juxtaposition, connotations, dual meaning words, repetition, enjambment, and types of irony. I name these devices specifically because they represent literary elements participants had limited knowledge about prior to our discussion. Most striking about the interaction in this final face-to-face workshop was how participants responded to peer review. Common reactions were "I hadn't noticed that until you pointed it out," or "I noticed that but didn't know the term for it." These responses opened our discussion of language devices, and in doing so, allowed us to attach names to the functions participants were already identifying in analyses. In this final face-to-face meeting, we observed, analyzed collaboratively, and found meaning on individual and shared levels.

Each writer, in the second phase of the online writing workshop, had to revise the previously workshopped piece and post the new version by week's end. In this second uploaded version of writing, authors had to address their peer's comments. Each participant had to describe what feedback she did and did not use during revision and why she made these choices. This strategy discouraged lazy or proud revisions while it also engaged the author in the very analysis process her peers experienced. Peers then re-analyzed the revised works, comparing both versions in their comments. This time I encouraged more use of literary language in the comments, guiding and redirecting when necessary. In this second round of peer interaction participants used literary language with more accuracy and confidence. Using Milica's revised story as an example, participants identified literary devices and noted how these devices informed the work. Our peer discussion of Milica's story centered on lyrical elements. Bethany responds to the opening exposition, writing, "Powerful alliteration here. Really highlights the emotional timbre of the moment." Katie replies, "I agree! This alliteration is seamless." Later in the piece, Katie writes, "I love the consistent moods and images you have presented throughout the piece ... [and] the ending you leave us with-I'm a huge fan of imagery/sound being the last sentence." Bethany adds, "This is my favorite sentence and an excellent metaphorical summary of the piece: 'she wants to crawl back into the dark, ashamed, while the pink dawn echoes the bloody reality."'

\section{Matching the Workshop to the Discourse}

After careful analysis of how literary language can be learned and used in the 
different types of workshop models, one might be tempted to argue the ways one is better than the other. Yet, the objective is not to prove one model as superior to another. The objective is to build a workshop model that best promotes the learning of literary language for our teaching situation. Like any teaching model, one size does not fit all. Knowledge of literary language and how it functions in texts is valuable to all members of society. Therefore, it makes sense to consider ways to best meet the needs of the student body in each environment. What will work best in today's college writing course is not necessarily what will work best in a continuing education course. In an adult enrichment learning environment, students may have more time to invest in learning and practicing literary language. This means face-to-face sessions can be extended if the conversations justify it. Online workshops might help set up more in depth face-to-face discussions influenced by pre-reading. Online interaction may provide more productive critiquing sessions where peers can continuously respond to each other's comments. An undergrad college level workshop, on the other hand, may be a part of a study program filled with students carrying full class loads. These larger loads place considerable limits on the required homework-loads-per-credit-hour guidelines. Less homework time could mean there simply will not be occasion at all for online interaction. A community outreach or rehabilitation setting might not have online access as an option. A lack of online resources then means all interaction must be face-to-face. In these situations we can see how different factors affect the ways writing workshops can be set up and how teaching strategies can be combined to meet the needs of the given learning situation. We can also see that through a diversity of reading and writing strategies, students do learn and use literary language in a workshop and by using the language, gain a better command of it.

\section{Conflicts of Interest}

The author declares no conflicts of interest regarding the publication of this paper.

\section{References}

[1] Cohen, P.M. (2012) Pop Studies: Glory at the Fountain of Coca Cola. Drexel University. www.thesmartset.com/article/article12091301.aspx

[2] Beacon Literacy Inc. (2010) About Reading and Reading Difficulties. Calgary, Alberta. http://www.literacycanada.com

[3] Scholes, R.E. (1985) Textual Power: Literary Theory and the Teaching of English. Yale University Press.

[4] Dawson, P. (2003) Towards a New Poetics in Creative Writing Pedagogy. University of New South Wales. www.textjournal.com.au/april03/dawson.htm

[5] Gross, P. (2010) Ch. 3: Small Worlds: What Works in Workshops If and When They Do? Does the Writing Workshop Still Work? In: Donnelly, D., Ed., Multilingual Matters, Bristol, Buffalo. https://trove.nla.gov.au/nbdid/45508169

[6] La Femina, G. (2011) Demystifying and Demythifying the Workshop: On the Sup- 
posed "Lore" of Creative Writing Pedagogy. Association of Writers \& Writing Programs.

https://www.awpwriter.org/magazine_media/writers_chronicle_issues/onlineonlyex clusives

[7] Haake, K. (2010) Ch. 14: Re-Envisioning the Workshop: Hybrid Classrooms, Hybrid Texts. Does the Writing Workshop Still Work? In: Donnelly, D., Ed., Multilingual Matters, Bristol, Buffalo. https://trove.nla.gov.au/version/50291192

[8] Gaffigan, M. (1995) Reinventing the Undergraduate Poetry Workshop: Results from a Nationwide Survey of Undergraduate Poetry Writing Instructors. Association of Writers \& Writing Programs.

[9] Thursby, J. (2002) Inquiry, Folkloristics, and Discussion: Unbinding Literature in the Classroom. In: Holden, J. and Schmit, J., Eds., Inquiry and the Literary Text. Constructing Discussions in the English Classroom. Classroompractices in Teaching English, National Council of Teachers of English.

http://files.eric.ed.gov/fulltext/ED471390.pdf 